OPEN ACCESS

Edited by:

Takumi Higaki,

The University of Tokyo, Japan

Reviewed by:

Samantha Vernhettes,

French National Institute

for Agricultural Research, France

Erika Isono,

Technische Universität München,

Germany

Arata Yoneda

Nara Institute of Science

and Technology, Japan

*Correspondence:

Kazuo Ebine

ebine@bs.s.u-tokyo.ac.jp

Specialty section:

This article was submitted to

Plant Physiology,

a section of the journal

Frontiers in Plant Science

Received: 10 February 2015 Accepted: 02 October 2015

Published: 19 October 2015

Citation:

Ebine $K$ and Ueda $T$ (2015) Roles of membrane trafficking in plant cell wall dynamics.

Front. Plant Sci. 6:878. doi: $10.3389 /$ fpls.2015.00878

\section{Roles of membrane trafficking in plant cell wall dynamics}

\author{
Kazuo Ebine ${ }^{1 *}$ and Takashi Ueda ${ }^{1,2}$ \\ ${ }^{1}$ Department of Biological Sciences, Graduate School of Science, The University of Tokyo, Tokyo, Japan, ${ }^{2}$ Japan Science \\ and Technology Agency, Precursory Research for Embryonic Science and Technology, Kawaguchi, Japan
}

The cell wall is one of the characteristic components of plant cells. The cell wall composition differs among cell types and is modified in response to various environmental conditions. To properly generate and modify the cell wall, many proteins are transported to the plasma membrane or extracellular space through membrane trafficking, which is one of the key protein transport mechanisms in eukaryotic cells. Given the diverse composition and functions of the cell wall in plants, the transport of the cell wall components and proteins that are involved in cell wall-related events could be specialized for each cell type, i.e., the machinery for cell wall biogenesis, modification, and maintenance could be transported via different trafficking pathways. In this review, we summarize the recent progress in the current understanding of the roles and mechanisms of membrane trafficking in plant cells and focus on the biogenesis and regulation of the cell wall.

Keywords: membrane trafficking, cell wall, transport mechanisms, RAB, exocyst, SNARE

\section{INTRODUCTION}

Membrane trafficking is a key mechanism for transporting proteins, lipids, and polysaccharides among organelles in plant cells (Fujimoto and Ueda, 2012). The key molecules involved in membrane trafficking are generally conserved among eukaryotic cells, and the specific diversification of machinery components for membrane trafficking has occurred in plants and is associated with the development of plant-specific transport pathways during plant evolution (Fujimoto and Ueda, 2012). The cell wall is a characteristic structure of plant cells, and the components of this structure differ among organs and cell types in plants. Recent studies indicate that the diversification of membrane trafficking contributes to cell wall differentiation in plant cells (Kim and Brandizzi, 2014). Herein, we present an overview of the recent findings on the pivotal roles of membrane trafficking in the biogenesis and regulation of the cell wall.

\section{MOLECULAR MECHANISMS UNDERLYING MEMBRANE TRAFFICKING IN PLANT CELLS}

Membrane trafficking is accomplished via three sequential steps: (1) vesicle budding from donor organelles, frequently involving coat protein complexes, such as COPI and COPII; (2) tethering the vesicles to the target membrane through activated Rab and Rab effectors; and (3) vesicle fusion with the target organelle, mediated through SNARE molecules (Ebine and Ueda, 2009; Fujimoto and Ueda, 2012; Figure 1). A majority of the proteins synthesized at the endoplasmic reticulum (ER) and polysaccharides synthesized in the Golgi are transported to the trans-Golgi network (TGN) and subsequently delivered to each organelle or the plasma membrane/extracellular space or traffic through the Golgi-independent trafficking pathway to the vacuole in plant cells 


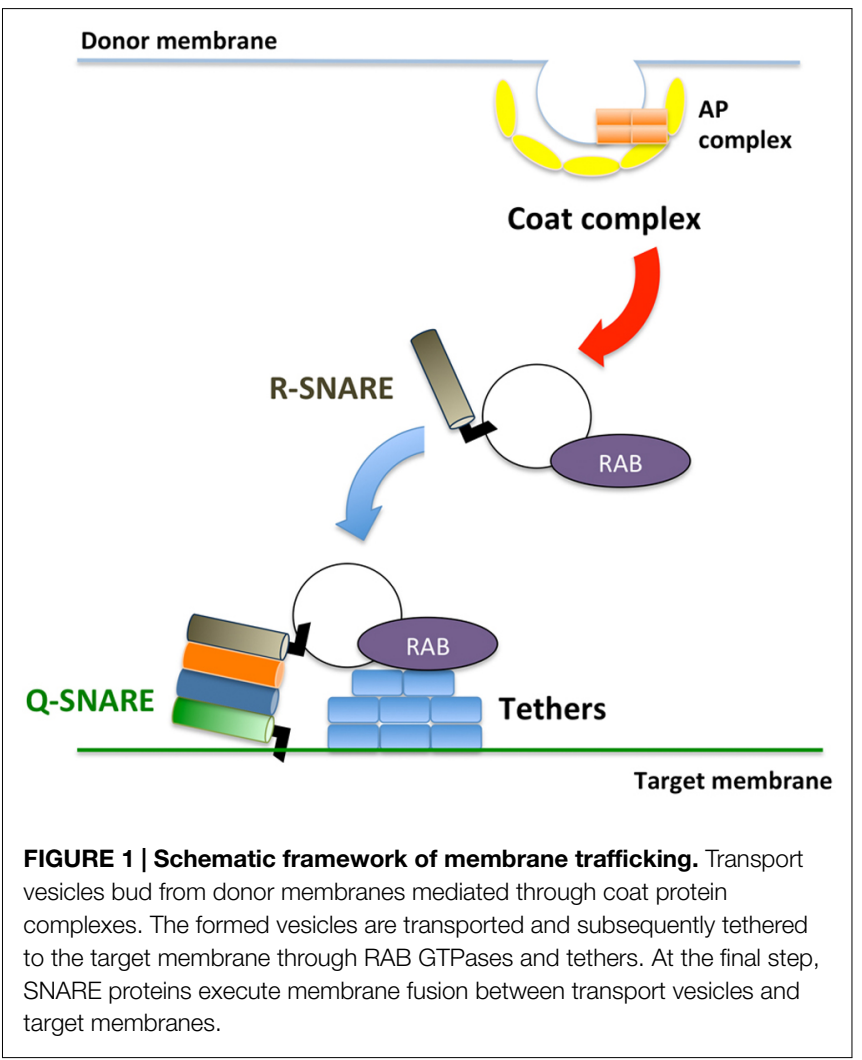

(Pedrazzini et al., 2013; Inada and Ueda, 2014). The direct interaction between the ER and plasma membrane has also been reported (Staehelin, 1997; Sparkes et al., 2011; Wang et al., 2014; Perez Sancho et al., 2015), although the exchange of molecules at this contact point has not been demonstrated in plants.

Two Rab GTPases, RAB8/RABE and RAB11/RABA, have been implicated in the regulation of the pathway that mediates transport to the plasma membrane in plant cells (Speth et al., 2009; Fujimoto and Ueda, 2012; Inada and Ueda, 2014). In mammalian and yeast cells, these two Rab GTPases sequentially regulate transport to the plasma membrane, and the exocyst complex acts as a tethering complex in the RAB11-RAB8 cascade (MizunoYamasaki et al., 2012). The exocyst complex comprises eight proteins that are responsible for tethering secretory vesicles to the plasma membrane (Synek et al., 2014). After the membrane vesicle is tethered to the plasma membrane, an R-SNARE protein on the vesicle and three Q-SNARE molecules on the plasma membrane assemble into a SNARE complex that executes membrane fusion between the membranes. Intriguingly, the number of genes encoding RAB11/RABA and a component of the exocyst complex, EXO70, is remarkably high in plants: $26 \mathrm{RAB} 11$, classified into six subgroups (RABA1-RABA6), and 23 EXO70, classified into eight subgroups (EXO70A-EXO70H), are encoded in the Arabidopsis genome (Chong et al., 2010; Fujimoto and Ueda, 2012).

A functional analysis of the RAB11 proteins in Nicotiana benthamiana leaf epidermal cells indicated that RABA1b regulates the transport pathway from the TGN to the plasma membrane but that RABA4c regulates transport from the plasma membrane to the TGN (Choi et al., 2013). This result suggests that each Rab11 subgroup regulates different transport pathways. ARA6/RABF1 is also involved in transport to the plasma membrane, although the specific cargo remains unclear (Ebine et al., 2011). Each EXO70 subgroup has also been implicated in the regulation of a different transport pathway in plant cells (Synek et al., 2014). Exo70A1 regulates transport to the plasma membrane, whereas EXO70B1 regulates the transport of autophagosomes to vacuoles (Synek et al., 2006; Kulich et al., 2010, 2013). EXO70E2 regulates an unconventional secretory pathway mediated through an autophagosome-like double membrane structure termed EXPO (Wang et al., 2010; Ding et al., 2014). These EXO70 members likely share the same exocyst core complex and have been implicated as targets for ubiquitin-mediated degradation (Zarsky et al., 2013). Moreover, some RAB11 and EXO70 members are expressed in specific organs and are likely associated with the cell type-specific differentiation of membrane trafficking pathways (Lycett, 2008; Chong et al., 2010; Asaoka et al., 2012; Synek et al., 2014).

The SYP1 group contains members of the Q-SNARE family, which function in membrane fusion events at the plasma membrane and cell plate. SYP1 proteins have been classified into three subgroups in seed plants: SYP11, SYP12, and SYP13 (Saito and Ueda, 2009; Kanazawa et al., 2015). SYP111, which is also known as KNOLLE in Arabidopsis, localizes to the cell plate and mediates membrane fusion during cell division (Lauber et al., 1997; Muller et al., 2003). Both SYP12 and SYP13 localize to the plasma membrane. However, SYP12, but not SYP13, accumulates at the focal site of the cell, which reflects a functional difference between SYP12 and SYP13. Whereas SYP132, which is the most abundantly and ubiquitously expressed SYP13 protein in Arabidopsis, localizes uniformly at the plasma membrane of the growing pollen tube and root hair, SYP12 proteins localize to distinctive parts of the pollen tube and root hair. SYP123 localizes to the tip of the root hair, and SYP124 and SYP125 localize to distinct parts of the pollen tube (Enami et al., 2009; Silva et al., 2010; Ul-Rehman et al., 2011; Ichikawa et al., 2014). An interactomic analysis also revealed that SYP1 proteins interact with distinct sets of proteins (Fujiwara et al., 2014), further supporting the functional differentiation among SYP1 members.

In addition to proteinaceous transport machinery components, lipids play critical roles in membrane trafficking. Phosphatidylinositol derivatives (PIs) are key molecules that determine the characteristics of membrane domains (Fujimoto and Tsutsumi, 2014; Krishnamoorthy et al., 2014). Interactions between PIs and binding proteins depend on the phosphorylation state of PIs, and the phosphorylation status of PIs is tightly regulated through phosphatases and kinases (Fujimoto and Tsutsumi, 2014; Krishnamoorthy et al., 2014). Phosphatidylinositol 4-kinase (PI4K) and 5-kinase (PI5K) accumulate at the tips of tip-growing cells, where these enzymes induce the accumulation of $\mathrm{PI}(4,5) \mathrm{P} 2$ and thereby contribute to the elongation of these cells and deposition of the cell wall materials at the tips by regulating actin dynamics (Preuss et al., 2006; Krishnamoorthy et al., 2014). These kinases also occasionally act as effector molecules of Rab GTPases; PI4K $\beta$ is an effector molecule of RABA4, and PI5K2 is an effector molecule of RABE1d (Camacho et al., 2009; Szumlanski and Nielsen, 2009; Antignani et al., 2015), which indicates a tight link between Rab GTPase and PI metabolism. 
Some proteins at the plasma membrane are endocytosed into the cytoplasm in response to the signals associated with extracellular conditions (Fujimoto and Tsutsumi, 2014). Clathrinmediated endocytosis involves clathrin and dynamin-related proteins, where adapter protein complex 2 (AP-2) mediates cargo loading and clathrin assembly in eukaryotic cells (McMahon and Boucrot, 2011). Recent studies have shown that plants also use another adaptor complex called TPLATE (Van Damme et al., 2011; Gadeyne et al., 2014; Zhang et al., 2015). During $\mathrm{NaCl}$ stress, the clathrin-independent endocytosis of PIP2;1, an aquaporin residing on the plasma membrane, has also been reported in plants (Li et al., 2011; Chevalier and Chaumont, 2014).

\section{MEMBRANE TRAFFIC REGULATING CELL WALL DEPOSITION}

Many cell wall-associated molecules, including cellulose synthase (CESA), callose synthase (CALS)/glucan synthase like (GSL), and pectin methylesterase (PME), are transported to the plasma membrane and/or extracellular compartment via membrane trafficking. The cellulose synthase complex (CSC), comprising CESA, synthesizes cellulose at the plasma membrane. Cellulose deposition is strictly regulated depending on cell types, developmental stages, and environmental changes, thus the subcellular localization of the CSC, which profoundly depends on membrane trafficking, should be tightly regulated (McFarlane et al., 2014a). The CSC harbors a rosette-like structure, which has previously been detected in the ER of the moss, Funaria hygrometrica (Rudolph, 1987). This evidence might indicate that the rosette-shaped CSC is assembled at the ER and subsequently transported to the plasma membrane via the unique compartment, MASC (microtubule-associated cellulose synthase compartment)/SmaCC (small CESA-containing compartments; Sampathkumar et al., 2013; Gonneau et al., 2014; Hill et al., 2014; Kim and Brandizzi, 2014; McFarlane et al., 2014a; Figure 2). The endocytic transport of the CSC has also been observed in other events. For example, CSC internalization, which is mediated through AP-2, occurs in response to osmotic changes (Crowell et al., 2009; Bashline et al., 2013; Fujimoto et al., 2015; Figure 2). A recent study showed that CESA3 endocytosis is inhibited through phenylarsine oxide (PAO), an inhibitor of PI4K, whereas LY294002, an inhibitor of PI3K, blocks the transport of CESA3 from the Golgi apparatus (Fujimoto et al., 2015), indicating distinct requirements of PIs in distinctive trafficking steps in CSC transport (Figure 2).

CALS/GSL synthesizes callose at the plasma membrane or cell plate (Ferguson et al., 1998). Polysaccharides other than cellulose and callose are synthesized at the Golgi and subsequently transported to the extracellular space. The processing and/or modification of polysaccharides also occur during transport to the extracellular space (Schoberer and Strasser, 2011; Oikawa et al., 2013). ECHIDNA (ECH), which is required for TGN function, is also important for the secretion of polysaccharides (Gendre et al., 2011, 2013; McFarlane et al., 2013, 2014b). Both ech and trs120-4, a mutant of the predicted

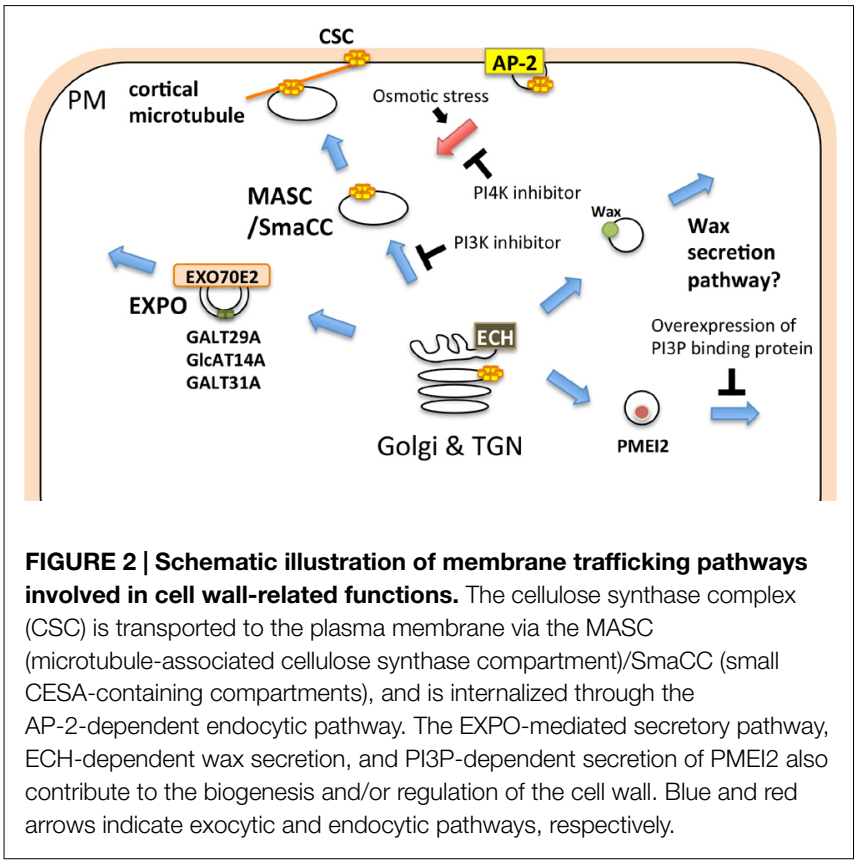

component of the RAB11 activation complex, exhibit a defect in general secretion, but only ech is defective in wax secretion (McFarlane et al., 2014b). Wax is synthesized at the ER and subsequently transported to the extracellular compartment (Haslam and Kunst, 2013). Thus, wax could be secreted via a different pathway than polysaccharides in plant cells (Figure 2). Furthermore, AtGALT31A, an arabinogalactan glycosyltransferase, localizes to Exo70E2-positive compartments, suggesting that this protein is secreted into the extracellular space through the EXPO (Poulsen et al., 2014; Figure 2). These results suggest that cell wall-related components are transported through diverse trafficking pathways. The involvement of the exocyst complex in secondary cell wall formation has also been reported. Exo70A1 is required for SCW formation during tracheary element formation (Li et al., 2013), and a recent study has also revealed a specific trafficking mechanism involving Exo70A1 in tracheary element formation (Oda et al., 2014).

The delivery of cell wall components is also strictly regulated during tip growth and cell plate formation. The CSC and CALS accumulate at the tip of the pollen tube (Cai et al., 2011), and this localization is maintained through targeted membrane trafficking at the tip of the pollen tube (Mollet et al., 2013; Onelli and Moscatelli, 2013). Pectin methylesterase inhibitor 2 (PMEI2) accumulates at the tip of the pollen tube, whereas pollenspecific pectin methylesterase1 (PPME1) localizes throughout the cell wall (Rockel et al., 2008). PMEI2 aggregates in the cytoplasmic compartment through the overexpression of the FYVE domain, a PI3P protein-binding domain. In contrast, the overexpression of the FYVE domain does not affect the secretion of PPME1 (Figure 2). These results indicate that PMEI2 and PPME1 are secreted through different pathways. In growing pollen tubes or root hair cells, many vesicles accumulate at the tip of the elongation zone, and these vesicles 
are labeled with RABA1 and/or RABA4 (Cole et al., 2005; de Graaf et al., 2005; Wen et al., 2005; Cole and Fowler, 2006; Asaoka et al., 2012; Caballero-Lima et al., 2013; Gu and Nielsen, 2013; Zhang et al., 2013), which suggests that these vesicles mediate secretion to the tips of growing cells, contributing to the focal elongation of these cells. RAB11, an ortholog of Arabidopsis RABA, regulates trafficking from the recycling endosome to the plasma membrane in animal cells (Wandinger-Ness and Zerial, 2014). Thus, either (or both) of the two subgroups of plant RAB11, RABA1, and RABA4 might regulate dynamic endocytosis and/or recycling at the tip region of the growing pollen tube.

The direction of membrane trafficking dynamically changes during cell plate formation (McMichael and Bednarek, 2013; Jurgens et al., 2015), and both secretory and endocytic pathways contribute to this process (McMichael and Bednarek, 2013; Jurgens et al., 2015). The adaptor complex 1 (AP-1) regulates transport to the vacuole in leaf cells and the transport of KNOLLE/SYP111 to the cell plate (Fujimoto and Ueda, 2012; Teh et al., 2013). A mutation in EXO84b, a component of the exocyst complex, induces the mislocalization of the polysaccharides recognized by JIM7 or LM14 in dividing cells in immunocytochemistry experiments (Rybak et al., 2014). This result indicates that exocyst-mediated secretion contributes to the transport of polysaccharides to the cell plate. The CSC and CALS also accumulate in the cell plate (Hong et al., 2001; Thiele et al., 2009; Miart et al., 2014). The CSC is transported to the newly formed cell wall via multiple pathways (Miart et al., 2014). Callose synthesis occurs at the cell plate during late anaphase, which is required for the completion of cell division (Thiele et al., 2009). CALS/GSL also accumulates at the cell plate (Hong et al., 2001), but the molecular mechanism of this localization remains unclear.

\section{REGULATION OF MEMBRANE COMPOSITION AND TRAFFICKING VIA THE CELL WALL}

Organelle membranes in both animal and plant cells comprise many microdomains (Martiniere and Runions, 2013; Yoshida

\section{REFERENCES}

Antignani, V., Klocko, A. L., Bak, G., Chandrasekaran, S. D., Dunivin, T., and Nielsen, E. (2015). Recruitment of PLANT U-BOX13 and the PI4Kbeta1/beta2 phosphatidylinositol-4 kinases by the small GTPase RabA4B plays important roles during salicylic acid-mediated plant defense signaling in Arabidopsis. Plant Cell 27, 243-616. doi: 10.1105/tpc.114.134262

Asaoka, R., Uemura, T., Ito, J., Fujimoto, M., Ito, E., Ueda, T., et al. (2012). Arabidopsis RABA1 GTPases are involved in transport between the trans-Golgi network and the plasma membrane, and are required for salinity stress tolerance. Plant J. 73, 240-249. doi: 10.1111/tpj.12023

Bashline, L., Li, S., Anderson, C. T., Lei, L., and Gu, Y. (2013). The endocytosis of cellulose synthase in Arabidopsis is dependent on mu2, a clathrinmediated endocytosis adaptin. Plant Physiol. 163, 150-160. doi: 10.1104/pp.113. 221234

Caballero-Lima, D., Kaneva, I. N., Watton, S. P., Sudbery, P. E., and Craven, C. J. (2013). The spatial distribution of the exocyst and actin cortical patches is sufficient to organize hyphal tip growth. Eukaryot. Cell 12, 998-1008. doi: 10.1128/EC.00085-13 et al., 2013; Jarsch et al., 2014; Konrad et al., 2014). Recent studies suggest that the cell wall possesses regulatory functions for the structure and function of the plasma membrane. The mobility of microdomains in the plasma membrane is regulated through interactions with actin filaments, and actin filament dynamics are regulated through $\mathrm{PI}(4,5) \mathrm{P} 2$ in animal cells (Kusumi et al., 2005; Krishnamoorthy et al., 2014). In plant cells, interactions with the cell wall likely represent key regulatory mechanisms for some microdomains (Martiniere et al., 2012; Martiniere and Runions, 2013). PIN1, an auxin efflux carrier, localizes to microdomains in the plasma membrane, and mutations in CESA3 induce the mislocalization of PIN1, expressed under the regulation of the PIN2 promoter (Feraru et al., 2011). A recent analysis of PMR4, a CALS that acts during the plant defense response, indicated that PMR4 interacts with RABA4c, promoting the localization of RABA4c at the plasma membrane (Ellinger et al., 2014). This result could represent a functional link between the focal accumulation of callose and targeted secretion upon pathogen attack. Thus, the integrity and/or composition of the cell wall and the membrane trafficking system affect each other, further indicating the tight linkage and mutual regulation between the plant cell wall and membrane trafficking.

\section{PERSPECTIVE}

As described above, various aspects of interaction between the plant cell wall and membrane trafficking have been reported. However, the underlying mechanisms remain unclear. In particular, the feedback mechanism of the regulation of membrane trafficking via the cell wall has essentially remained unexplored. There are also many open questions concerning the molecular mechanisms underlying the transport of cell wall components through distinct trafficking pathways. For example, how and where are cell wall components sorted for loading onto different trafficking intermediates? Further extensive research in this area is needed to obtain a precise understanding of the tight linkage between the cell wall and membrane trafficking.

Cai, G., Faleri, C., Del Casino, C., Emons, A. M., and Cresti, M. (2011). Distribution of callose synthase, cellulose synthase, and sucrose synthase in tobacco pollen tube is controlled in dissimilar ways by actin filaments and microtubules. Plant Physiol. 155, 1169-1190. doi: 10.1104/pp.110. 171371

Camacho, L., Smertenko, A. P., Perez-Gomez, J., Hussey, P. J., and Moore, I. (2009). Arabidopsis Rab-E GTPases exhibit a novel interaction with a plasma-membrane phosphatidylinositol-4-phosphate 5-kinase. J. Cell Sci. 122, 4383-4392. doi: $10.1242 /$ jcs. 053488

Chevalier, A. S., and Chaumont, F. (2014). Trafficking of plant plasma membrane aquaporins: multiple regulation levels and complex sorting signals. Plant Cell Physiol. 56, 819-829. doi: 10.1093/pcp/pcu203

Choi, S. W., Tamaki, T., Ebine, K., Uemura, T., Ueda, T., and Nakano, A. (2013). RABA members act in distinct steps of subcellular trafficking of the FLAGELLIN SENSING2 receptor. Plant Cell 25, 1174-1187. doi: 10.1105/tpc.112. 108803

Chong, Y. T., Gidda, S. K., Sanford, C., Parkinson, J., Mullen, R. T., and Goring, D. R. (2010). Characterization of the Arabidopsis thaliana exocyst complex gene families by phylogenetic, expression profiling, and subcellular 
localization studies. New Phytol. 185, 401-419. doi: 10.1111/j.1469-8137.2009. 03070.x

Cole, R. A., and Fowler, J. E. (2006). Polarized growth: maintaining focus on the tip. Curr. Opin. Plant Biol. 9, 579-588. doi: 10.1016/j.pbi.2006. 09.014

Cole, R. A., Synek, L., Zarsky, V., and Fowler, J. E. (2005). SEC8, a subunit of the putative Arabidopsis exocyst complex, facilitates pollen germination and competitive pollen tube growth. Plant Physiol. 138, 2005-2018. doi: 10.1104/pp.105.062273

Crowell, E. F., Bischoff, V., Desprez, T., Rolland, A., Stierhof, Y. D., Schumacher, K., et al. (2009). Pausing of Golgi bodies on microtubules regulates secretion of cellulose synthase complexes in Arabidopsis. Plant Cell 21, 1141-1154. doi: $10.1105 /$ tpc. 108.065334

de Graaf, B. H., Cheung, A. Y., Andreyeva, T., Levasseur, K., Kieliszewski, M., and Wu, H. M. (2005). Rab11 GTPase-regulated membrane trafficking is crucial for tip-focused pollen tube growth in tobacco. Plant Cell 17, 2564-2579. doi: $10.1105 /$ tpc. 105.033183

Ding, Y., Wang, J., Chun Lai, J. H., Ling Chan, V. H., Wang, X., Cai, Y., et al. (2014), Exo70E2 is essential for exocyst subunit recruitment and EXPO formation in both plants and animals. Mol. Biol. Cell 25, 412-426. doi: 10.1091/mbc.E13-100586

Ebine, K., Fujimoto, M., Okatani, Y., Nishiyama, T., Goh, T., Ito, E., et al. (2011). A membrane trafficking pathway regulated by the plant-specific RAB GTPase ARA6. Nat. Cell Biol. 13, 853-859. doi: 10.1038/ncb2270

Ebine, K., and Ueda, T. (2009). Unique mechanism of plant endocytic/vacuolar transport pathways. J. Plant Res. 122, 21-30. doi: 10.1007/s10265-0080200-x

Ellinger, D., Glockner, A., Koch, J., Naumann, M., Sturtz, V., Schutt, K., et al. (2014). Interaction of the Arabidopsis GTPase RabA4c with its effector PMR4 results in complete penetration resistance to powdery mildew. Plant Cell 26, 3185-3200. doi: $10.1105 /$ tpc. 114.127779

Enami, K., Ichikawa, M., Uemura, T., Kutsuna, N., Hasezawa, S., Nakagawa, T., et al. (2009). Differential expression control and polarized distribution of plasma membrane-resident SYP1 SNAREs in Arabidopsis thaliana. Plant Cell Physiol. 50, 280-289. doi: 10.1093/pcp/pcn197

Feraru, E., Feraru, M. I., Kleine-Vehn, J., Martiniere, A., Mouille, G., Vanneste, S., et al. (2011). PIN polarity maintenance by the cell wall in Arabidopsis. Curr. Biol. 21, 338-343. doi: 10.1016/j.cub.2011.01.036

Ferguson, C., Teeri, T. T., Siika-Aho, M., Read, S. M., and Bacic, A. (1998). Location of cellulose and callose in pollen tubes and grains of Nicotiana tabacum. Planta 206, 452-460. doi: 10.1007/s004250050421

Fujimoto, M., Suda, Y., Vernhettes, S., Nakano, A., and Ueda, T. (2015). Phosphatidylinositol 3-kinase and 4-kinase have distinct roles in intracellular trafficking of cellulose synthase complex in Arabidopsis thaliana. Plant Cell Physiol. 56, 287-298. doi: 10.1093/pcp/pcu195

Fujimoto, M., and Tsutsumi, N. (2014). Dynamin-related proteins in plant postGolgi traffic. Front. Plant Sci. 5:408. doi: 10.3389/fpls.2014.00408

Fujimoto, M., and Ueda, T. (2012). Conserved and plant-unique mechanisms regulating plant post-Golgi traffic. Front. Plant Sci. 3:197. doi: 10.3389/fpls.2012. 00197

Fujiwara, M., Uemura, T., Ebine, K., Nishimori, Y., Ueda, T., Nakano, A., et al. (2014). Interactomics of Qa-SNARE in Arabidopsis thaliana. Plant Cell Physiol. 55, 781-789. doi: 10.1093/pcp/pcu038

Gadeyne, A., Sanchez-Rodriguez, C., Vanneste, S., Di Rubbo, S., Zauber, H., Vanneste, K., et al. (2014). The TPLATE adaptor complex drives clathrin-mediated endocytosis in plants. Cell 156, 691-704. doi: 10.1016/j.cell. 2014.01.039

Gendre, D., McFarlane, H. E., Johnson, E., Mouille, G., Sjodin, A., Oh, J., et al. (2013). Trans-Golgi network localized ECHIDNA/Ypt interacting protein complex is required for the secretion of cell wall polysaccharides in Arabidopsis. Plant Cell 25, 2633-2646. doi: 10.1105/tpc.113. 112482

Gendre, D., Oh, J., Boutte, Y., Best, J. G., Samuels, L., Nilsson, R., et al. (2011). Conserved Arabidopsis ECHIDNA protein mediates trans-Golgi-network trafficking and cell elongation. Proc. Natl. Acad. Sci. U.S.A. 108, 8048-8053. doi: 10.1073/pnas.1018371108

Gonneau, M., Desprez, T., Guillot, A., Vernhettes, S., and Hofte, H. (2014). Catalytic subunit stoichiometry within the cellulose synthase complex. Plant Physiol. 166, 1709-1712. doi: 10.1104/pp.114.250159
Gu, F., and Nielsen, E. (2013). Targeting and regulation of cell wall synthesis during tip growth in plants. J. Integr. Plant Biol. 55, 835-846. doi: 10.1111/jipb. 12077

Haslam, T. M., and Kunst, L. (2013). Extending the story of very-long-chain fatty acid elongation. Plant Sci. 210, 93-107. doi: 10.1016/j.plantsci.2013. 05.008

Hill, J. L. Jr., Hammudi, M. B., and Tien, M. (2014). The Arabidopsis cellulose synthase complex: a proposed hexamer of CESA trimers in an equimolar stoichiometry. Plant Cell 26, 4834-4842. doi: 10.1105/tpc.114. 131193

Hong, Z., Delauney, A. J., and Verma, D. P. (2001). A cell plate-specific callose synthase and its interaction with phragmoplastin. Plant Cell 13, 755-768. doi: 10.1105/tpc.13.4.755

Ichikawa, M., Hirano, T., Enami, K., Fuselier, T., Kato, N., Kwon, C., et al. (2014). Syntaxin of plant proteins SYP123 and SYP132 mediate root hair tip growth in Arabidopsis thaliana. Plant Cell Physiol. 55, 790-800. doi: 10.1093/pcp/ pcu048

Inada, N., and Ueda, T. (2014). Membrane trafficking pathways and their roles in plant-microbe interactions. Plant Cell Physiol. 55, 672-686. doi: 10.1093/pcp/pcu046

Jarsch, I. K., Konrad, S. S., Stratil, T. F., Urbanus, S. L., Szymanski, W., Braun, P., et al. (2014). Plasma membranes are subcompartmentalized into a plethora of coexisting and diverse microdomains in Arabidopsis and Nicotiana benthamiana. Plant Cell 26, 1698-1711. doi: 10.1105/tpc.114. 124446

Jurgens, G., Park, M., Richter, S., Touihri, S., Krause, C., El Kasmi, F., et al. (2015). Plant cytokinesis: a tale of membrane traffic and fusion. Biochem. Soc. Trans. 43, 73-78. doi: 10.1042/BST20140246

Kanazawa, T., Era, A., Minamino, N., Shikano, Y., Fujimoto, M., Uemura, T., et al. (2015). SNARE molecules in Marchantia polymorpha: unique and conserved features of the membrane fusion machinery. Plant Cell Physiol. in press. doi: $10.1093 /$ pcp/pcr076

Kim, S. J., and Brandizzi, F. (2014). The plant secretory pathway: an essential factory for building the plant cell wall. Plant Cell Physiol. 55, 687-693. doi: 10.1093/pcp/pct197

Konrad, S. S., Popp, C., Stratil, T. F., Jarsch, I. K., Thallmair, V., Folgmann, J., et al. (2014). $S$-acylation anchors remorin proteins to the plasma membrane but does not primarily determine their localization in membrane microdomains. New Phytol. 203, 758-769. doi: 10.1111/nph.12867

Krishnamoorthy, P., Sanchez-Rodriguez, C., Heilmann, I., and Persson, S. (2014). Regulatory roles of phosphoinositides in membrane trafficking and their potential impact on cell-wall synthesis and re-modelling. Ann. Bot. 114, 1049-1057. doi: 10.1093/aob/mcu055

Kulich, I., Cole, R., Drdova, E., Cvrckova, F., Soukup, A., Fowler, J., et al. (2010). Arabidopsis exocyst subunits SEC8 and EXO70A1 and exocyst interactor ROH1 are involved in the localized deposition of seed coat pectin. New Phytol. 188, 615-625. doi: 10.1111/j.1469-8137.2010.03372.x

Kulich, I., Pecenkova, T., Sekeres, J., Smetana, O., Fendrych, M., Foissner, I., et al. (2013). Arabidopsis exocyst subcomplex containing subunit EXO70B1 is involved in autophagy-related transport to the vacuole. Traffic 14, 1155-1165. doi: $10.1111 /$ tra.12101

Kusumi, A., Nakada, C., Ritchie, K., Murase, K., Suzuki, K., Murakoshi, H., et al. (2005). Paradigm shift of the plasma membrane concept from the two-dimensional continuum fluid to the partitioned fluid: high-speed single-molecule tracking of membrane molecules. Annu. Rev. Biophys. Biomol. Struct. 34, 351-378. doi: 10.1146/annurev.biophys.34.040204. 144637

Lauber, M. H., Waizenegger, I., Steinmann, T., Schwarz, H., Mayer, U., Hwang, I., et al. (1997). The Arabidopsis KNOLLE protein is a cytokinesis-specific syntaxin. J. Cell Biol. 139, 1485-1493. doi: 10.1083/jcb.139.6.1485

Li, S., Chen, M., Yu, D., Ren, S., Sun, S., Liu, L., et al. (2013). EXO70A1-mediated vesicle trafficking is critical for tracheary element development in Arabidopsis. Plant Cell 25, 1774-1786. doi: 10.1105/tpc.113.112144

Li, X., Wang, X., Yang, Y., Li, R., He, Q., Fang, X., et al. (2011). Singlemolecule analysis of PIP2;1 dynamics and partitioning reveals multiple modes of Arabidopsis plasma membrane aquaporin regulation. Plant Cell 23, 3780-3797. doi: 10.1105/tpc.111.091454

Lycett, G. (2008). The role of Rab GTPases in cell wall metabolism. J. Exp. Bot. 59, 4061-4074. doi: 10.1093/jxb/ern255 
Martiniere, A., Lavagi, I., Nageswaran, G., Rolfe, D. J., Maneta-Peyret, L., Luu, D. T., et al. (2012). Cell wall constrains lateral diffusion of plant plasmamembrane proteins. Proc. Natl. Acad. Sci. U.S.A. 109, 12805-12810. doi: 10.1073/pnas.1202040109

Martiniere, A., and Runions, J. (2013). Protein diffusion in plant cell plasma membranes: the cell-wall corral. Front. Plant Sci. 4:515. doi: 10.3389/fpls.2013.00515

McFarlane, H. E., Doring, A., and Persson, S. (2014a). The cell biology of cellulose synthesis. Annu. Rev. Plant Biol. 65, 69-94. doi: 10.1146/annurev-arplant050213-040240

McFarlane, H. E., Watanabe, Y., Yang, W., Huang, Y., Ohlrogge, J., and Samuels, A. L. (2014b). Golgi- and trans-Golgi network-mediated vesicle trafficking is required for wax secretion from epidermal cells. Plant Physiol. 164, 1250-1260. doi: $10.1104 /$ pp.113.234583

McFarlane, H. E., Watanabe, Y., Gendre, D., Carruthers, K., Levesque-Tremblay, G., Haughn, G. W., et al. (2013). Cell wall polysaccharides are mislocalized to the Vacuole in echidna mutants. Plant Cell Physiol. 54, 1867-1880. doi: $10.1093 / \mathrm{pcp} / \mathrm{pct} 129$

McMahon, H. T., and Boucrot, E. (2011). Molecular mechanism and physiological functions of clathrin-mediated endocytosis. Nat. Rev. Mol. Cell Biol. 12, 517-533. doi: $10.1038 / \mathrm{nrm} 3151$

McMichael, C. M., and Bednarek, S. Y. (2013). Cytoskeletal and membrane dynamics during higher plant cytokinesis. New Phytol. 197, 1039-1057. doi: 10.1111/nph.12122

Miart, F., Desprez, T., Biot, E., Morin, H., Belcram, K., Hofte, H., et al. (2014). Spatio-temporal analysis of cellulose synthesis during cell plate formation in Arabidopsis. Plant J. 77, 71-84. doi: 10.1111/tpj.12362

Mizuno-Yamasaki, E., Rivera-Molina, F., and Novick, P. (2012). GTPase networks in membrane traffic. Annu. Rev. Biochem. 81, 637-659. doi: 10.1146/annurevbiochem-052810-093700

Mollet, J.-C., Leroux, C., Dardelle, F., and Lehner, A. (2013). Cell wall composition, biosynthesis and remodeling during pollen tube growth. Plants 2, 107-147. doi: 10.3390/plants2010107

Muller, I., Wagner, W., Volker, A., Schellmann, S., Nacry, P., Kuttner, F., et al. (2003). Syntaxin specificity of cytokinesis in Arabidopsis. Nat. Cell Biol. 5, 531-534. doi: 10.1038/ncb991

Oda, Y., Iida, Y., Nagashima, Y., Sugiyama, Y., and Fukuda, H. (2014). Novel coiledcoil proteins regulate exocyst association with cortical microtubules in xylem cells via the conserved oligomeric golgi-complex 2 protein. Plant Cell Physiol. 56, 277-286. doi: 10.1093/pcp/pcu197

Oikawa, A., Lund, C. H., Sakuragi, Y., and Scheller, H. V. (2013). Golgi-localized enzyme complexes for plant cell wall biosynthesis. Trends Plant Sci. 18, 49-58. doi: $10.1016 /$ j.tplants.2012.07.002

Onelli, E., and Moscatelli, A. (2013). Endocytic pathways and recycling in growing pollen tubes. Plants 2, 211-229. doi: 10.3390/plants2020211

Pedrazzini, E., Komarova, N. Y., Rentsch, D., and Vitale, A. (2013). Traffic routes and signals for the tonoplast. Traffic 14, 622-628. doi: 10.1111/tra.12051

Perez Sancho, J., Vanneste, S., Lee, E., McFarlane, H., Esteban Del Valle, A., Valpuesta, V., et al. (2015). The Arabidopsis SYT1 is enriched in ER-PM contact sites and confers cellular resistance to mechanical stresses. Plant Physiol. 168, 132-143. doi: 10.1104/pp.15.00260

Poulsen, C. P., Dilokpimol, A., Mouille, G., Burow, M., and Geshi, N. (2014). Arabinogalactan glycosyltransferases target to a unique subcellular compartment that may function in unconventional secretion in plants. Traffic 15, 1219-1234. doi: 10.1111/tra.12203

Preuss, M. L., Schmitz, A. J., Thole, J. M., Bonner, H. K., Otegui, M. S., and Nielsen, E. (2006). A role for the RabA4b effector protein PI- $4 \mathrm{~K} \beta 1$ in polarized expansion of root hair cells in Arabidopsis thaliana. J. Cell Biol. 172, 991-998. doi: $10.1083 /$ jcb. 200508116

Rockel, N., Wolf, S., Kost, B., Rausch, T., and Greiner, S. (2008). Elaborate spatial patterning of cell-wall PME and PMEI at the pollen tube tip involves PMEI endocytosis, and reflects the distribution of esterified and de-esterified pectins. Plant J. 53, 133-143. doi: 10.1111/j.1365-313X.2007. 03325.x

Rudolph, U. (1987). Occurrence of rosettes in the ER membrane of young Funaria hygrometrica protonemata. Naturwissenschaften 74, 439-439. doi: 10.1007/BF00446099

Rybak, K., Steiner, A., Synek, L., Klaeger, S., Kulich, I., Facher, E., et al. (2014). Plant cytokinesis is orchestrated by the sequential action of the TRAPPII and exocyst tethering complexes. Dev. Cell 29, 607-620. doi: 10.1016/j.devcel.2014. 04.029

Saito, C., and Ueda, T. (2009). Chapter 4: functions of RAB and SNARE proteins in plant life. Int. Rev. Cell Mol. Biol. 274, 183-233. doi: 10.1016/S19376448(08)02004-2

Sampathkumar, A., Gutierrez, R., McFarlane, H. E., Bringmann, M., Lindeboom, J., Emons, A. M., et al. (2013). Patterning and lifetime of plasma membranelocalized cellulose synthase is dependent on actin organization in Arabidopsis interphase cells. Plant Physiol. 162, 675-688. doi: 10.1104/pp.113. 215277

Schoberer, J., and Strasser, R. (2011). Sub-compartmental organization of Golgiresident $\mathrm{N}$-glycan processing enzymes in plants. Mol. Plant 4, 220-228. doi: $10.1093 / \mathrm{mp} / \mathrm{ssq} 082$

Silva, P. A., Ul-Rehman, R., Rato, C., Di Sansebastiano, G. P., and Malho, R. (2010). Asymmetric localization of Arabidopsis SYP124 syntaxin at the pollen tube apical and sub-apical zones is involved in tip growth. BMC Plant Biol. 10:179. doi: 10.1186/1471-2229-10-179

Sparkes, I., Hawes, C., and Frigerio, L. (2011). FrontiERs: movers and shapers of the higher plant cortical endoplasmic reticulum. Curr. Opin. Plant Biol. 14, 658-665. doi: 10.1016/j.pbi.2011.07.006

Speth, E. B., Imboden, L., Hauck, P., and He, S. Y. (2009). Subcellular localization and functional analysis of the Arabidopsis GTPase RabE. Plant Physiol. 149, 1824-1837. doi: 10.1104/pp.108.132092

Staehelin, L. A. (1997). The plant ER: a dynamic organelle composed of a large number of discrete functional domains. Plant J. 11, 1151-1165. doi: 10.1046/j.1365-313X.1997.11061151.x

Synek, L., Schlager, N., Elias, M., Quentin, M., Hauser, M. T., and Zarsky, V. (2006). AtEXO70A1, a member of a family of putative exocyst subunits specifically expanded in land plants, is important for polar growth and plant development. Plant J. 48, 54-72. doi: 10.1111/j.1365-313X.2006. 02854.x

Synek, L., Sekeres, J., and Zarsky, V. (2014). The exocyst at the interface between cytoskeleton and membranes in eukaryotic cells. Front. Plant Sci. 4:543. doi: 10.3389/fpls.2013.00543

Szumlanski, A. L., and Nielsen, E. (2009). The Rab GTPase RabA4d regulates pollen tube tip growth in Arabidopsis thaliana. Plant Cell 21, 526-544. doi: 10.1105/tpc.108.060277

Teh, O. K., Shimono, Y., Shirakawa, M., Fukao, Y., Tamura, K., Shimada, T., et al. (2013). The AP-1 mu adaptin is required for KNOLLE localization at the cell plate to mediate cytokinesis in Arabidopsis. Plant Cell Physiol. 54, 838-847. doi: $10.1093 / \mathrm{pcp} / \mathrm{pct} 048$

Thiele, K., Wanner, G., Kindzierski, V., Jurgens, G., Mayer, U., Pachl, F., et al. (2009). The timely deposition of callose is essential for cytokinesis in Arabidopsis. Plant J. 58, 13-26. doi: 10.1111/j.1365-313X.2008.03760.x

Ul-Rehman, R., Silva, P. A., and Malho, R. (2011). Localization of Arabidopsis SYP125 syntaxin in the plasma membrane sub-apical and distal zones of growing pollen tubes. Plant Signal. Behav. 6, 665-670. doi: 10.4161/psb.6.5. 14423

Van Damme, D., Gadeyne, A., Vanstraelen, M., Inze, D., Van Montagu, M. C., De Jaeger, G., et al. (2011). Adaptin-like protein TPLATE and clathrin recruitment during plant somatic cytokinesis occurs via two distinct pathways. Proc. Natl. Acad. Sci. U.S.A. 108, 615-620. doi: 10.1073/pnas. 1017890108

Wandinger-Ness, A., and Zerial, M. (2014). Rab proteins and the compartmentalization of the endosomal system. Cold Spring Harb. Perspect. Biol. 6, a022616. doi: 10.1101/cshperspect.a022616

Wang, J., Ding, Y., Wang, J., Hillmer, S., Miao, Y., Lo, S. W., et al. (2010). EXPO, an exocyst-positive organelle distinct from multivesicular endosomes and autophagosomes, mediates cytosol to cell wall exocytosis in Arabidopsis and tobacco cells. Plant Cell 22, 4009-4030. doi: 10.1105/tpc.110. 080697

Wang, P., Hawkins, T. J., Richardson, C., Cummins, I., Deeks, M. J., Sparkes, I., et al. (2014). The plant cytoskeleton, NET3C, and VAP27 mediate the link between the plasma membrane and endoplasmic reticulum. Curr. Biol. 24, 1397-1405. doi: $10.1016 /$ j.cub.2014.05.003

Wen, T. J., Hochholdinger, F., Sauer, M., Bruce, W., and Schnable, P. S. (2005). The roothairless1 gene of maize encodes a homolog of sec3, which is involved in polar exocytosis. Plant Physiol. 138, 1637-1643. doi: 10.1104/pp.105. 062174 
Yoshida, K., Ohnishi, M., Fukao, Y., Okazaki, Y., Fujiwara, M., Song, C., et al. (2013). Studies on vacuolar membrane microdomains isolated from Arabidopsis suspension-cultured cells: local distribution of vacuolar membrane proteins. Plant Cell Physiol. 54, 1571-1584. doi: 10.1093/pcp/pct107

Zarsky, V., Kulich, I., Fendrych, M., and Pecenkova, T. (2013). Exocyst complexes multiple functions in plant cells secretory pathways. Curr. Opin. Plant Biol. 16, 726-733. doi: 10.1016/j.pbi.2013.10.013

Zhang, Y., Immink, R., Liu, C. M., Emons, A. M., and Ketelaar, T. (2013). The Arabidopsis exocyst subunit SEC3A is essential for embryo development and accumulates in transient puncta at the plasma membrane. New Phytol. 199, 74-88. doi: $10.1111 /$ nph. 12236

Zhang, Y., Persson, S., Hirst, J., Robinson, M. S., Van Damme, D., and SanchezRodriguez, C. (2015). Change your TPLATE, change your fate: plant CME and beyond. Trends Plant Sci. 20, 41-48. doi: 10.1016/j.tplants.2014.09.002
Conflict of Interest Statement: The authors declare that the research was conducted in the absence of any commercial or financial relationships that could be construed as a potential conflict of interest. The Review Editor Samantha Vernhettes declares that, despite having collaborated with the author Takashi Ueda within the past two years, the review was handled objectively. The Guest Associate Editor Masaru Fujimoto declares that, despite being affiliated with the same institute as the author Kazuo Ebine, the review process was handled objectively.

Copyright $\odot 2015$ Ebine and Ueda. This is an open-access article distributed under the terms of the Creative Commons Attribution License (CC BY). The use, distribution or reproduction in other forums is permitted, provided the original author(s) or licensor are credited and that the original publication in this journal is cited, in accordance with accepted academic practice. No use, distribution or reproduction is permitted which does not comply with these terms. 